Special Issue of the 8th International Advances in Applied Physics and Materials Science Congress (APMAS 2018)

\title{
Seismic Vulnerability Assessment of Reinforced Concrete Frame Structure by Finite Element Analysis
}

\author{
M. Hadzima-Nyarko*, D. Nikić And G. Pavić \\ Department of Materials and Structures, Faculty of Civil Engineering and Architecture Osijek, \\ University J.J. Strossmayer in Osijek, 31000 Osijek, Croatia
}

\begin{abstract}
Performance of structures depends on the vulnerability of the structure and the seismic hazard of the region. As part of the Mediterranean-Transasian belt, the Croatian territory is located in an earthquake prone area. Implementation of earthquake-resistant building design rules is essential in order to mitigate the damages of earthquakes affecting settlement areas. Performance-based evaluation of buildings may be conducted through fragility curves developed for different levels of performance. In this paper, a reinforced concrete frame structure was designed as a moderately ductile building according to EN 1998-1:2004. Incremental dynamic analysis of the nonlinear numerical reinforced concrete model is implemented in the software package SeismoStruct, wherein the frame elements (column, beam) were defined as finite elements. The seismic risk of the model is estimated by probabilistic analysis that takes the randomness of seismic excitation into account and evaluates the probability of exceeding a certain critical condition. Seven real time histories selected from European Strong-motion Database were used. The structural behaviour is observed based on maximum interstorey drifts through the entire height of the building for each seismic excitation. The results obtained by incremental dynamic analysis of the nonlinear numerical model are also compared with an empirical seismic vulnerability method - macroseismic method.
\end{abstract}

DOI: 10.12693/APhysPolA.135.845

PACS/topics: finite element method; incremental dynamic analysis, macroseismic method, reinforced concrete frame, seismic vulnerability

\section{Introduction}

Croatia is located in the area of occurrence of destructive earthquakes that have been recorded for the past two thousand years. For more than half of the Croatian territory $(56.22 \%)$ inhabited by more than one third (1.633.529) of the total current Croatian population is characterized as a zone with a high risk of occurrence of earthquakes [1]. The assessment of the impact of an earthquake on the built environment can only be accomplished by detecting the structural systems of buildings and their performance in past earthquakes, engineering standards adopted during construction and the location and distribution of vulnerable building stock in the shaken area. A high proportion of building stock in Croatia, of which the majority is either masonry or concrete, was built after World War II. For example, in paper [2], in which earthquake risk was assessed for primary schools in Osijek city, it was given that $82.7 \%$ are reinforced concrete $(\mathrm{RC})$ framed structures. In paper [3], in which earthquake risk was assessed for kindergartens in Osijek city, 20\% of those buildings were RC frames. In order to mitigate the damages of earthquakes affecting settlement areas, it is essential to implement earthquake-resistant building design rules. Therefore, an $\mathrm{RC}$ frame structure was designed as a moderately ductile building according to European norm EN 1998-1:2004 (Eurocode 8, EC8), accepted as the Croatian norm

\footnotetext{
*corresponding author; e-mail: mhadzima@gfos.hr
}

HRN EN 1998-1:2011 [4], in order to demonstrate that the correct design of RC frame structures increases earthquake resistance of the structures.

\section{The finite elements modeling of RC frame structure}

The selected building was built in 2014 as a reinforced concrete frame structure of a total height of $6 \mathrm{~m}$ (Fig. 1), consisting of two floors extending over four spans. RC frame model was designed in accordance with the European norm EN 1998-1:2004, accepted as the Croatian norm HRN EN 1998-1:2011 [4]. Dynamic analysis of nonlinear numerical model was performed using the software package SeismoStruct, ver. 7.0.6 [5].

The frame elements (beams and columns) are defined by finite elements with attributed geometric and material nonlinearities. For simulation of nonlinear behavior of concrete and steel, the Mander model (1988) and the

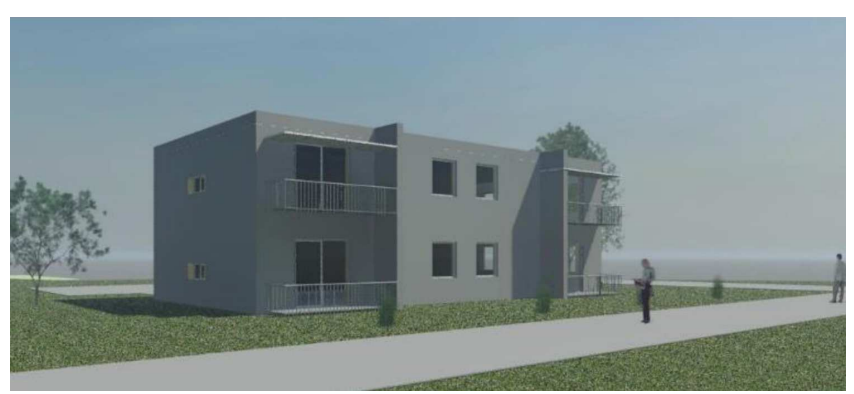

Fig. 1. Analyzed RC framed building. 


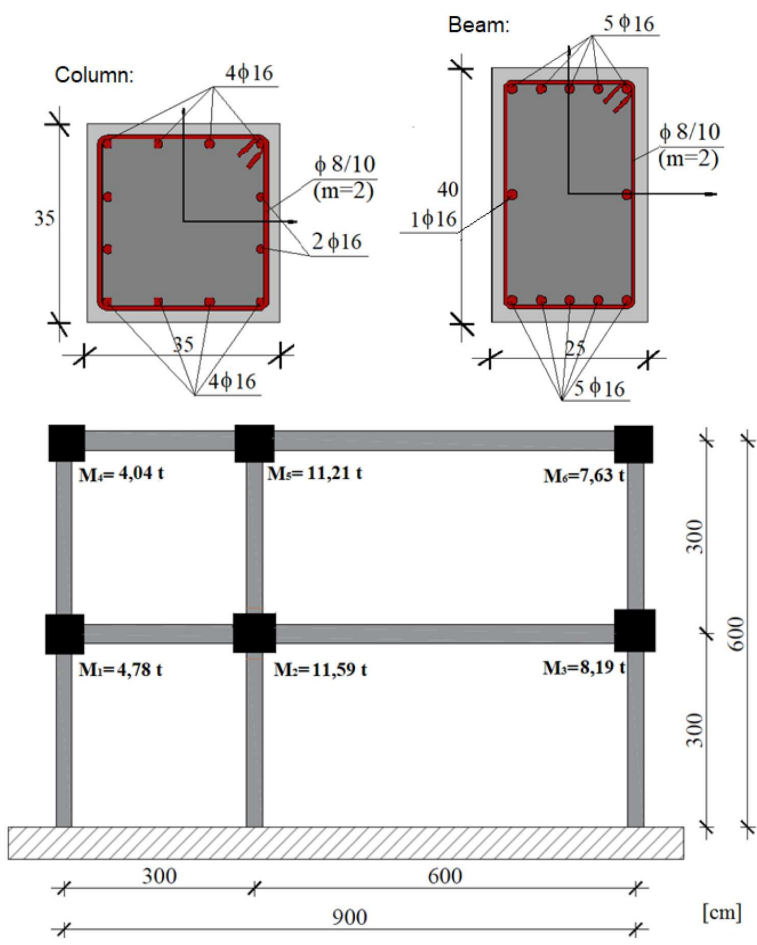

Fig. 2. RC framed model with cross section reinforcement.

Menegotto-Pinto model (1973) were used, respectively. Steel B500B and concrete C30/37 concrete were used. Model dimensions and the details of the reinforcement of the beams and columns are shown in Fig. 2.

In dynamic analysis, input data consisted of set of seven real ground motion records selected from the European Strong-motion Database using REXEL 3.5 software [6]. The ground motion records are selected based on the target spectrum type 1 , soil type B, with a peak ground acceleration of 0.1g, defined in EN 1998-1:2004 (Fig. 3).

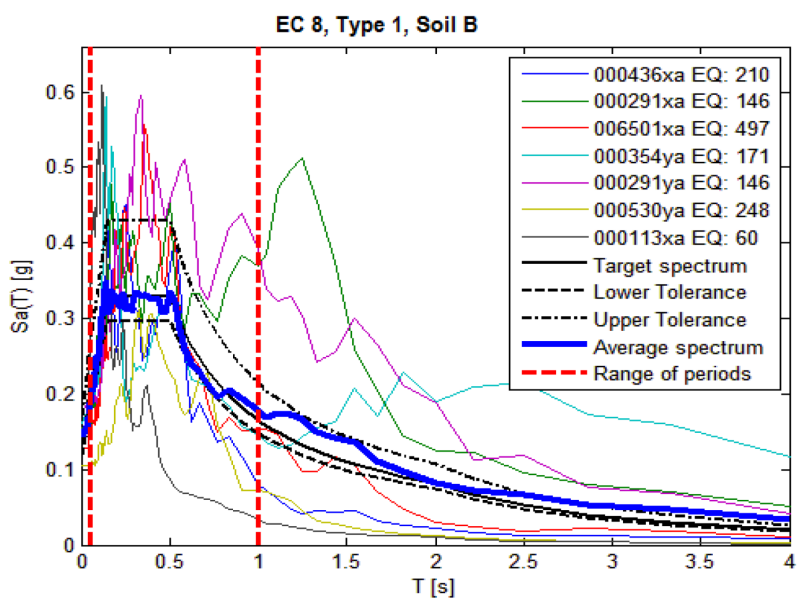

Fig. 3. Response spectrum with $5 \%$ damping for seven ground motion records.
Nonlinear dynamic analyses of the structural model implies that each ground motion record is scaled to several intensity levels designed to force the structure all the way from elasticity to final global dynamic instability [7]. IDA curves of the structural response are generated, as measured by a maximum peak interstorey drift $\left(I D R_{\max }\right)$, versus the ground motion intensity level, measured by the peak ground acceleration (PGA). Seismic response has been analysed considering maximum $I D R_{\max }$ as main damage measure. Damage states (slight, moderate, extensive and collapse) are associated eligibility conditions expressed in the terms of $I D R_{\max }(0.40 \%$, $1.0 \%, 1.8 \%$ and $3.0 \%$ ) according to the proposal of Ghobarah [8]. Limit-states can be defined on each IDA curve and summarized to produce the probability of exceeding a specified limit-state given the intensity measure level. Parameters for defining the lognormal distribution model are formed for all four limit damage states, which will ultimately result in four damage probability curves for four damage states.

\section{Seismic vulnerability assessment using macroseismic method}

Macroseismic method, as an example of empirical method, uses parameters which influence the building vulnerability. i.e. plan, type and quality of materials, type of foundation, structural and non-structural elements etc. The seismic action is defined in terms of macroseismic intensity. The building's seismic quality is described by means of a vulnerability index $V_{I}$, which depends on the behavior of its structural system and it involves other modifiers as follows [9]:

$$
V_{I}=V_{I}^{*}+V_{r}+V_{m}
$$

where $V_{I}^{*}$ is the typological vulnerability index, $V_{r}$ is the regional vulnerability modifier and $V_{m}$ is the behavior modifier. For each typology, a vulnerability index (VI) is defined by a most likely value $V_{I}^{*}$ (e.g. the typological vulnerability index), the most plausible value for the specific building type, which is computed as the centroid of the membership function. The behavior modifier, $V_{m}$, which modifies building vulnerability, is associated to geometrical features of the building (number of stories, foundation, plan irregularities, irregularities in vertical planes) and the state of conservation and the propsed values are between -0.04 to +0.04 , which means that the final value of vulnerability index will be decreased or increased. A regional vulnerability factor, $V_{r}$, takes into account building typologies at a regional level, which affects vulnerability due to traditional constructive techniques in different regions. The value of the typological vulnerability index is 0.484 (Table I) for the observed RC frame with moderate earthquake resistance (marked as RC2) according to [9]. Analyzing the proposed behavior modifiers (number of storeys, state of preservation, plan irregularity, vertical irregularity, foundation and presence of short columns), the vulnerability index will be reduced by -0.02 because it is a low building. The total value of 
the vulnerability index is then 0.464 . An analytic expression is defined for the operational implementation of the methodology; accordingly the mean damage grade, $\mu_{D}$, is defined as a function of the macroseismic intensity $I$ and depends on two parameters: the vulnerability index $V_{I}$ and the ductility index $Q$ (with recommended value of 2.3) [9]:

$$
\mu_{D}=2.5\left(1+\tanh \left(\frac{\left.I+6.25 V_{I}-13.1\right)}{Q}\right)\right) .
$$

TABLE I

Vulnerability index values for building typologies according to [9]

\begin{tabular}{l|l|c|l|l|l|l|l}
\hline \hline \multicolumn{1}{c|}{ Typology } & $\begin{array}{c}\text { Building } \\
\text { type }\end{array}$ & $V^{--}$ & $V^{-}$ & $V_{I}^{*}$ & $V^{+}$ & $V^{++}$ \\
\hline $\begin{array}{l}\text { reinforced } \\
\text { concrete }\end{array}$ & $\mathrm{RC} 2$ & $\begin{array}{c}\text { frame in r.c. } \\
\text { (moderate } \\
\text { E.R.D.) }\end{array}$ & 0.14 & 0.33 & 0.484 & 0.64 & 0.86 \\
\hline
\end{tabular}

\section{Results and discussion}

\subsection{Results of dynamic analysis of nonlinear numerical model}

IDA curves, i.e. the relation $I D R_{\max }$ versus PGA, are generated and presented in Fig. 4, which illustrates almost linear behavior for the Friuli earthquake at higher intensity levels. For other earthquake records, a highly nonlinear structure response is expected, i.e. the structure will most likely collapse. Figure 4 shows the dispersion of results in the dynamic response of the structure also. Based on such a dispersion of the results it can be concluded that a greater number of earthquakes have to be considered in order to obtain the most credible mean value of all dynamic structural responses. From the results of analytical computation, it is possible to determine structural capacities corresponding to various limit states.

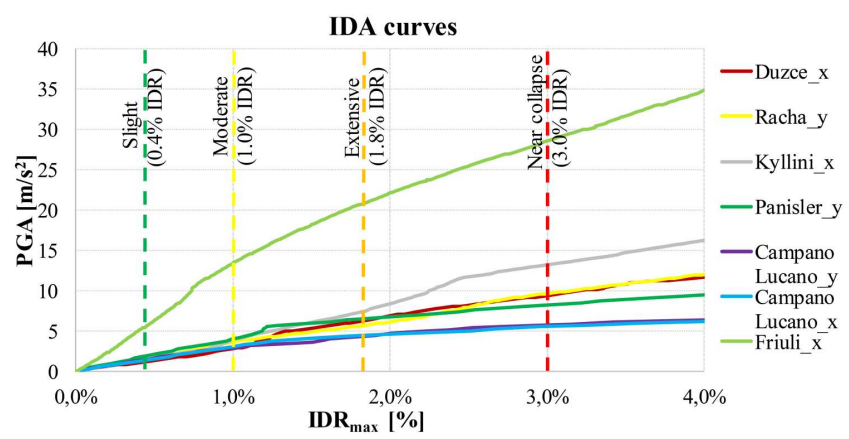

Fig. 4. IDA curves.

Probability of building damage is calculated using Fragility curves (Fig. 5). The abscissa in the coordinate system denotes the peak acceleration, whereas the

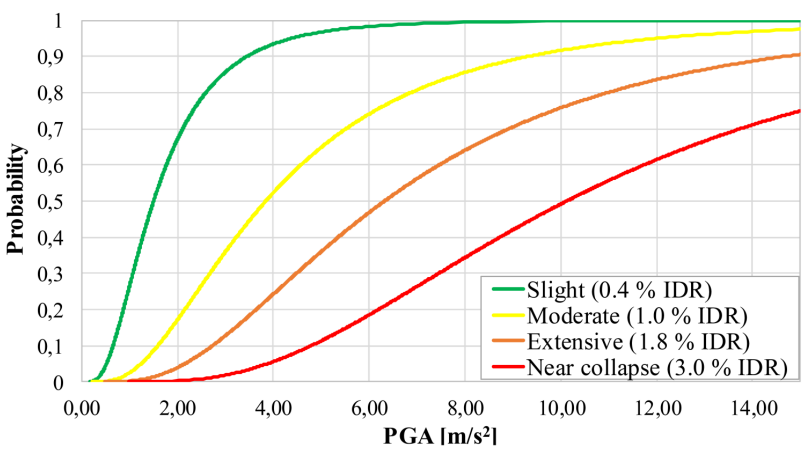

Fig. 5. Fragility curves.

ordinate displays the conditional values denoting that a certain damage condition is either reached $\left(P\left[D_{s}=d_{s}\right]\right)$ or exceeded $\left(P\left[D_{s}>d_{s}\right]\right)$. Thereby, Fragility curves are obtained using the log-normal distribution, median, and standard deviation. Damage probability curves are converted into probability matrices by using the terms (3), from which probability values of individual damage degree $\left(P\left(d_{s}-i_{m}\right)\right.$ are obtained and which correspond to the damage probability matrix.

$$
\begin{gathered}
P\left(d_{s} \mid i m\right)= \\
\begin{cases}1-P\left(D_{s} \geq d_{s} \mid i m\right) & i=0 \\
P\left(D_{s} \geq d_{s} \mid i m\right)-P\left(D_{s} \geq d_{s(i+1)} \mid i m\right) & 0<i<n \\
P\left(D_{s} \geq d_{s} \mid i m\right) & i=n\end{cases}
\end{gathered}
$$

where $i_{m}$ is the level of intensity measurements, $d_{s}$ displays the structural damage level, and $D_{s}$ stands for the state of the damage.

Table II shows that for the peak acceleration of $0.1 \mathrm{~g}$, for all seven earthquakes, the probability that the structure will not be damaged is $73 \%$, the probability of being slightly damaged is $24 \%$, probability of moderate damage is $2.7 \%$, extensive damage $0.3 \%$ and the probability of a collapse is $0 \%$. For peak acceleration $0.2 g$, probability that the structure will not be damaged is $33 \%$, probability of being slightly damaged is $50 \%$, moderate damage $13 \%$, extensive damage $3.7 \%$ and the probability of a collapse is $0.3 \%$. For peak acceleration $0.3 \mathrm{~g}$ it is obtained that the probability that the structure will not be damaged is $14 \%$, slightly damaged is $50 \%$, while the probability of being moderately damaged is $23 \%$, extensive damage $11 \%$ and the probability of a collapse is $2 \%$.

TABLE II

Probability damage matrices obtained by Dynamic analysis of nonlinear numerical model

\begin{tabular}{c|c|c|c|c|c}
\hline $\begin{array}{c}\text { Building } \\
\text { type }\end{array}$ & \multicolumn{5}{|c}{ Structural performance levels } \\
\hline RC1 & $\begin{array}{c}\text { No } \\
\text { damage }\end{array}$ & $\begin{array}{c}\text { Slight } \\
(0.4 \% I D R)\end{array}$ & $\begin{array}{c}\text { Moderate } \\
(1.0 \% \text { IDR })\end{array}$ & $\begin{array}{c}\text { Extensive } \\
(1.8 \% I D R)\end{array}$ & $\begin{array}{c}\text { Near } \\
\text { collapse } \\
(3 \% I D R)\end{array}$ \\
\hline $0.1 \mathrm{~g}$ & 0.73 & 0.24 & 0.027 & 0.003 & 0.00 \\
$0.2 \mathrm{~g}$ & 0.33 & 0.50 & 0.13 & 0.037 & 0.003 \\
$0.3 \mathrm{~g}$ & 0.14 & 0.50 & 0.23 & 0.11 & 0.02
\end{tabular}




\subsection{Results of macroseismic method}

For three level of intensities (VII, VIII and IX), mean damage grade, $\mu_{D}$, was calculated using the Eq. (2). The values of obtained mean damage grade, $\mu_{D}$, are presented in Table III.

For the calculated mean damage grades, $\mu_{D}$, the damage probability matrices are obtained using binomial distribution. The values of probability damage matrices are presented in Table IV for three levels of intensity (VII, VIII and IX).

Mean damage grade, $\mu_{D}$, obtained

TABLE III for analyzed MRF building

\begin{tabular}{c|c|c|c}
\hline \hline Intensity & VII & VIII & IX \\
\hline mean damage grade $\mu_{D}$ & 0.2914 & 0.6432 & 1.3024
\end{tabular}

Probability damage matrices obtained

TABLE IV

by macroseismic method

\begin{tabular}{c|c|c|c|c|c|c}
\hline $\begin{array}{c}\text { Building } \\
\text { type }\end{array}$ & \multicolumn{6}{|c}{ Damage grades } \\
\hline RC1 & 0 & 1 & 2 & 3 & 4 & 5 \\
\hline VII & 0.7407 & 0.2292 & 0.00284 & 0.0018 & 0.0001 & 0.00 \\
VIII & 0.5023 & 0.3708 & 0.1095 & 0.0162 & 0.0012 & 0.00 \\
IX & 0.2212 & 0.3895 & 0.2744 & 0.0967 & 0.0170 & 0.0012
\end{tabular}

Comparison of results between both methods shows that, for the degree of intensity VII, which corresponds to peak ground acceleration of about $0.1 \mathrm{~g}$, will remain almost undamaged. The comparison shows that a $1.4 \%$ difference between the analytical and macroseismic methods was obtained. The difference between the analytical and macroseismic methods for slight damage is $4.7 \%$.

For VIII degree of intensity, probability that the building will remain undamaged is $50.2 \%$ according to the macroseismic method, and $23 \%$ by analytical method. The probability of slight damage is $37 \%$ according to the macroseismic method, and $50 \%$ according to the analytical method, which makes a difference of $35 \%$. The probability that the building will be moderately damaged by the macroseismic method is $3 \%$, whereas by analytical is $13 \%$.

For degree of intensity IX, probability that the building will remain undamaged is $22 \%$ according to the macroseismic method, and $14 \%$ by the analytical method, making the difference of $52 \%$ between the methods. The probability that the building will be slightly damaged is $39 \%$ according to the macroseismic method, and $50 \%$ according to the analytical method, while the probability that the building will be moderately damaged is $27 \%$ according to the macroseismic method and $23 \%$ according to the analytical method. The probability that the building will be extensively damaged is $10 \%$ according to the macroseismic method or $11 \%$ by analytical method. The probability that the building will be completely damaged is $0.1 \%$ according to the macroseismic method, and $2 \%$ according to the analytical method.

\section{Conclusion}

In order to analyse the inelastic limit states in performance-based seismic engineering, a new approach has been proven to be viable solution - IDA. This approach relies on the performance of a sequence of nonlinear dynamic analyses of structural models involving numerous records which are each scaled to several intensity levels that are selected accordingly in order to reveal the whole behavior range of the model: starting from elastic to yielding and to nonlinear inelastic, and all the way up to global dynamic instability. An RC frame structure was designed as a moderately ductile building according to EC8 in order to demonstrate that the correct design of $\mathrm{RC}$ frame structures has increased earthquake resistance of the structures. The article outlines the importance of proper design and following building codes as well as the fact that empirical and analytical methods give results that can be significantly different and difficult to compare.

\section{References}

[1] M. Hadzima-Nyarko, G. Pavić, M. Lešić, Earthq. Struct. 11, 629 (2016).

[2] A. Antičević, M. Hadzima-Nyarko, A. Rabi, in: Proc. of the 4 th International Scientific Symposium "Economy of eastern Croatia — vision and growth", Osijek, Croatia 2015, p. 642.

[3] N. Ivandić, M. Hadzima-Nyarko, T. Štefić, in: Proc. of the 4th International Scientific Symposium "Economy of eastern Croatia - vision and growth", Osijek, Croatia 2015, p. 651.

[4] EN 1998-1:2004 (2004), Design of structures for earthquake resistance, Part I: General rules, seismic actions and rules for buildings, CEN - European Committee for Standardization, December 2004, Brussels (accepted as Croatian norm HRN EN 1998$1: 2011)$.

[5] SeismoStruct: A Computer Program for Static and Dynamic Nonlinear Analysis of Framed Structures, Technical report Seismosoft Ltd, Pavia, Italy.

[6] I. Iervolino, C. Galasso, E. Cosenza, Bull. Earthq. Eng. 8, 339 (2009).

[7] D. Vamvatsikos, C.A. Cornell, J. Struct. Eng. 131, 589 (2005).

[8] A. Ghobarah, in: International Workshop on Performance-Based Seismic Design, Eds. P. Fajfar, H. Krawinkler, Pacific Earthquake Engineering Research Center, Berkeley 2004.

[9] S. Lagomarsino, S. Giovinazzi, Bull. Earthq. Eng. 4, 415 (2006). 